\title{
ARTHROSCOPIC ACROMIOPLASTY FOR TREATMENT OF SHOULDER IMPINGEMENT SYNDROME
}

\author{
Ahmed A Hefny, Mohammed H Nasef, Yousuf M Khira, and Mohammed Abd Abdelsalam. \\ Orthopedic Department, Zagazig University, Egypt
}

\begin{abstract}
Background: The technique of arthroscopic subacromial decompression (ASD) is an effective alternative to the open operation. The arthroscopic procedure is technically demanding.

Patients and methods: Between January 2016 and February 2018, sixteen male patients, who fulfilled the criteria of the subacromial impingement syndrome, underwent arthroscopy, stability testing under anesthesia and arthroscopic acromioplasty. Pain was the chief complaint of every patient in this study. We used modified UCLA shoulder rating scale for clinical evaluation of the all patients. Pre-operative radiographs included an AP and axillary views added to $30^{\circ}$ caudal tilt view or a supraspinatus outlet view were done routinely. MRI of the shoulder was done for all cases.

Results: Satisfactory results were achieved in all patients and 6 of them were excellent according to UCLA score. Eight patients had good results and two fair, but no poor results were found in this study up to one year postoperative. Pain relief was the most dramatic benefit but function also improved. The subacromial space of the patients was filled with hypertrophic fibrous bands of bursal stroma, often with fibro-fatty tissue. Hyperemia was often observed. Surface ulcerations were identified on the rotator cuff in 8 cases. Rotator cuff partial tear in 4 cases.

Conclusion: In cases of primary impingement, calcific tendinitis, or partial thickness rotator cuff tears the arthroscopic acromioplasty and decompression, is the procedure of choice provided that no shoulder instability. The right indications and skilled hands, the results are better than the results of open acromioplasty, as the patients recover faster with less risk of deltoid muscle complications.
\end{abstract}

Key words: arthroscopic, acromioplasty, impingement, shoulder.

\section{INTRODUCTION}

A cromioplasty for the treatment of chronic impingement syndrome in the shoulder has been well documented ${ }^{1-7}$. The arthroscopic technique was first performed in 1983 with a preliminary report, and a short-term follow-up study of 50 cases suggested that the technique of arthroscopic subacromial decompression (ASD) is an effective alternative to the open operation. The arthroscopic procedure is technically demanding ${ }^{8-10}$.

When properly performed in patients with appropriate indications, hospitalization is brief, return to activities is rapid, there is little risk of deltoid muscle complications, and the results are lasting ${ }^{11-13}$.

The arthroscope is introduced in the glenohumeral joint which is filled with saline to allow visualization. The subacromial space can also be viewed on screen and any inflamed subacromial bursa removed via a bursectomy. A high speed burr is deployed to trim the anterior inferior undersurface of the acromion to prevent impingement. The idea is not to shorten the acromion undersurface but to smoothen it by shaving off any bony spur irregularities. If necessary, the distal $1 \mathrm{~cm}$ of the clavicle together with any surrounding osteophytes can be resected with the surgical burr. Over time, the space between the acromion and clavicle fills with scar tissue which strengthens and stabilizes the ACJ ${ }^{\mathbf{1 4}, 15}$. The aim of this prospective study is to evaluate the results of ASD in a group of 16 cases.

\section{PATIENTS AND METHODS}

Between January 2016 and February 2018, sixteen male patients, who fulfilled the criteria of the subacromial impingement syndrome, underwent arthroscopy, stability testing under anesthesia and arthroscopic 
acromioplasty in Zagazig university hospitals. The mean age of the patients was 32 years ranged from 25 to 40 years. Three of these patients had stage III impingement and were excluded; the remaining 16 patients had stage II impingement.

The dominant shoulder was involved in 12 patients. Follow-up was ranged from six months to one year. Night pain was a significant complaint in 14 of the patients. The mean duration of symptoms prior to surgery was 14 months (range 10-24 months). Two-thirds of these patients had crepitus about the shoulder during passive movements.

The clinical examination consisted of measuring the range of motion in flexion, abduction, and external and internal rotation. Muscle strength was tested manually and graded normal or decreased, and isometric pain provocations were done.

Pain was the chief complaint of every patient in this study. We used modified UCLA shoulder rating scale (Table 1) for clinical evaluation of the all patients 17 . In this system, pain and function are each rated, independently, on a scale of 1 to 10 , with 1 being the worst possible score, and 10 being awarded to a symptom-free shoulder. Range of motion, muscle strength, and patient satisfaction are also included, giving a maximum value of 5 points each. The maximum score on the UCLA scale would (35 points). Results were divided into excellent (34 to 35 points), good (28 to 33 ), fair (21 to 27 ), and poor (20 or less points). Good or excellent scores (> 28) were considered 'satisfactory', while fair or poor scores were 'unsatisfactory'. Conservative treatment was carried out in all patients for a minimum of six months (average one year) prior to surgery. This consisted of oral nonsteroidal anti-inflammatory drugs in every patient who could tolerate them, local steroid injections in 10 patients, and physical therapy. All patients in this study had undergone prolonged physiotherapy prior to operation. No standard regime of conservative treatment had been employed. The average preoperative UCLA score was 20 points (16-24), indicating that the patient was 'restricted to light work.

The Neer (I983) ${ }^{3}$ impingement sign was present in all patients, and was a necessary physical finding for establishing the diagnosis. In clinical assessment of the patients, impingement test was performed on all patients using approximately I $0 \mathrm{cc}$ of I\% lignocaine injected directly into the subacromial space. Prompt and profound diminution of symptoms from the injection was also a prerequisite for establishing the diagnosis, which was then confirmed arthroscopically prior to decompression. 
Table 1: UCLA Score.

\begin{tabular}{|c|c|}
\hline 1. Name of instrument & UCLA Shoulder Rating Scale \\
\hline $\begin{array}{l}\text { 2. What it is designed to assess } \\
\text { (specific anatomic area) }\end{array}$ & Shoulder \\
\hline $\begin{array}{l}\text { 3. Method of administration } \\
\text { (patient, clinician, or combined) }\end{array}$ & Combined \\
\hline 4. How to obtain the instrument & $\begin{array}{l}\text { Ellman H. Arthroscopic subacromial decompression: } \\
\text { analysis of one- to three-year results. Arthroscopy. } \\
1987 ; 3: 173-180 \text {. }\end{array}$ \\
\hline 5. Cost involved in obtaining instrument & None \\
\hline 6. Method of design & None \\
\hline 7. Statistical validation & None \\
\hline 8. Normative data available & None \\
\hline 9. Disease-specific data available & None \\
\hline \multirow[t]{3}{*}{$\begin{array}{l}10 \text {. References for scientific basis and } \\
\text { reference data }\end{array}$} & $\begin{array}{l}\text { Amstutz HC, Sew Hoy AL, Clarke IC. UCLA } \\
\text { anatomic total shoulder arthroplasty. Clin Orthop. } \\
\text { 1981;155:7-20. }\end{array}$ \\
\hline & $\begin{array}{l}\text { Kirkley A, Griffin S, Dainty K. ISAKOS Scientific } \\
\text { Committee Report: scoring systems for the functional } \\
\text { assessment of the shoulder. Arthroscopy. } \\
2003 ; 19: 1109-1120 \text {. }\end{array}$ \\
\hline & $\begin{array}{l}\text { Placzek JD, Lukens SC, Badalanmenti S et al. } \\
\text { Shoulder outcome measures: a comparison of } 6 \\
\text { functional tests. Am J Sports Med. } \\
2004 ; 32: 1270-1277 \text {. }\end{array}$ \\
\hline 11. Scoring module & None \\
\hline $\begin{array}{l}\text { 12. What kind of total and subscales } \\
\text { do you get }\end{array}$ & Total \\
\hline 13. Format and number of questions & Summated Rating scale, 5 questions \\
\hline 14. Time for administration & Not documented \\
\hline 15. Additional notes & $\begin{array}{l}\text { Best score }=35 \\
\text { There are two versions in the literature. Included } \\
\text { version is more current version. } \\
\text { Initially designed for total shoulder arthroplasty } \\
\text { patients. }\end{array}$ \\
\hline 16. The questionnaire & See page $\mathbf{S 1 4 0}$ \\
\hline
\end{tabular}

Radiology:

Pre-operative radiographs included an AP and axillary views added to $30^{\circ}$ caudal tilt view or a supraspinatus outlet view were done routinely. MRI of the shoulder was done for all cases. A spur was seen on the undersurface of the anterior aspect of the acromion in 4 patients. Calcific deposits were seen in the rotator cuffs of 4 patients.

All the study patients had an MRI of the shoulder at baseline before randomization. The patients' shoulders were scanned with an MRI at baseline. The acromial shape was evaluated according to Bigliani 18 as Type 1: straight or flat; Type 2: curved; or Type 3: hooked on sagittal
MRI scans using at least two of the most lateral slices of the acromion. The tendons were evaluated for tendinosis and possible tears. The muscle volume quantity was estimated using a method developed by Lehtinen et al $2003^{\mathbf{1 0}}$. in which the muscle volume is calculated based on the area of two T1- weighted sagittal scans. The volume is also estimated by the Tangent sign method ${ }^{16}$.

The fatty degeneration of the muscles was graded according to Goutallier method using T1-weighted sagittal MRI slices. The grading of fatty degeneration was divided into five steps: Stage 0 corresponds to a completely normal muscle, without any fatty streaks; in Stage 1 the muscle contains 
some fatty streaks; in Stage 2 the fatty infiltration is clear but there is still more muscle than fat; in Stage 3 there is as much fat as muscle; and in Stage 4 more fat than muscle is present 16

$\mathrm{AC}$ and glenohumeral degeneration were analyzed paying attention to cartilage thinning, joint space, sclerosis, osteophyte formation, subchondral cyst formation, and pathological joint effusion. Based on these findings, degeneration was staged according to the criteria published by Gahunia et al. into three stages: no/mild, moderate, and severe degeneration ${ }^{17}$.

\section{STATISTICAL ANALYSES}

Data were analyzed using the IBM SPSS Statistics for Windows, Version 19.0 for analysis. Descriptive statistics are presented as percentages, frequencies, and means with SD or medians with quartiles. A p-value <0.05 was considered statistically significant.

\section{Ethical considerations}

Cooperative patients fulfilling the criteria were asked to sign a written consent in which they voluntarily agreed to comply with the randomized treatment protocol and follow-up visits. The study was approved by the Ethics Committee of the Hospital District (Kanta- Häme Central Hospital E9/2001, 11 April 2001).

\section{Operative technique:}

All arthroscopic decompressions were performed by experienced orthopedic surgeons in arthroscopy unit in our orthopedic department. An interscalenic or supraclavicular brachial plexus block was applied for regional anesthesia in 6 patients, and general anesthesia for the remaining 10 patients.

Bony landmarks were palpated and marked. Glenohumeral stability and passive range of motion were tested (Fig. 1).

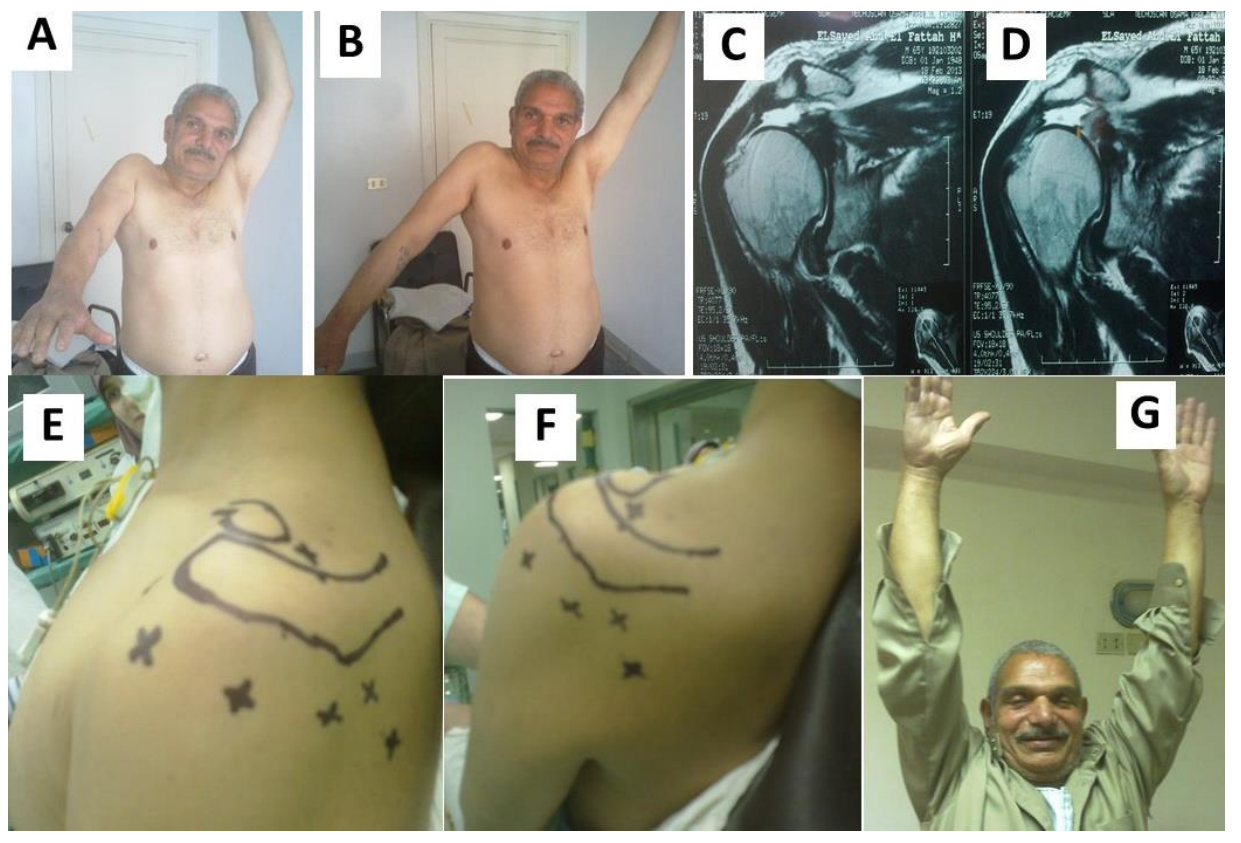

Figure 1) Case no.3: A,B) preoperative photo shows limitation of abduction range due to impingement, C,D) MRI preoperative, E,F) operative position and landmarks, G) postoperative range of painless abduction 6 months postoperative. 
The arthroscope was introduced into the joint through a standard posterior portal and a systematic recording of the articular cartilage, labrum and ligaments, biceps tendon, and the intra-articular rotator cuff was performed. The same standard portal was used to reach the subacromial space. Debridement and decompression were done through an anterolateral portal with a shaver and/or vaporizer. If the coracoacromial ligament felt tight or thick, it was released. Acromioplasty was performed starting anteriorly and progressing posterolaterally with a burr drill. The range of motion was tested under arthroscopic visualization to check for any local impingement.

\section{Postoperative phase}

The patients stayed at the hospital overnight. Postoperatively patients received IV analgesia and pain killer first day postoperative, then received antiinflammatory analgesics, usually ibuprofen. A collar cuff was used for a week. Mobilization was allowed with free active movements, starting with gravity- assisted rotating movements. Sutures and tapes were removed after 14 days, after which the patients received similar training instructions as were provided for the exercise group. After this, these patients were also subjected to a similar physiotherapeutic treatment and training session schedule described above, and they started their active training progressively. The training program was likewise individually planned and progressive. It was started progressively once the postoperative pain had gradually diminished. As in the supervised exercise treatment group, the progress was evaluated during physiotherapy controls, which averaged six in number.

\section{RESULTS}

Satisfactory results were achieved in all patients and 6 of them were excellent according to UCLA score. Eight patients had good results and two fair, but no poor results were found in this study up to one year postoperative. Pain relief was the most dramatic benefit but function also improved. The mean pain improved from 3 preoperative to 8.6 postoperative. Fourteen of the sixteen shoulders became completely pain free $(\%)$. Postoperative function averaged 8.9 on the UCLA scale (compared with 5.2 before operation). This implies the ability to perform activities of daily living (including driving, shopping and dressing), and to work above shoulder level with only, on occasion, slight restrictions. Twelve patients reported no functional restrictions at all (\%). Preoperative forward flexion (average $140^{\circ}$ ) improved to $160^{\circ}$ postoperatively (range $125^{\circ}$ to $180^{\circ}$ ). This change was statistically significant ( $\mathrm{p}$ value: 0.05). All patients in this series returned to activities of daily living within 10 (7-14) days of their operation. Postoperatively, the patients had arm sling for 1 week, and they were encouraged to use the arm. The patients returned to their jobs in an average duration of 21-45 days according to nature of work. Those patients' required repetitive overhead activities, especially strenuous lifting, usually took six weeks to 8 weeks. In this study there were all patients have returned to their regular job. No collegiate or professional athletes in this series.

No attempt was made to correlate the extent of surgical pathology with the postoperative result, but impingement was verified in each patient prior to operation.

Arthroscopic findings:

The subacromial space of the patients was filled with hypertrophic fibrous bands of bursal stroma, often with fibrofatty tissue. Hyperemia was often observed. Surface ulcerations were identified on the rotator cuff in 8 cases. Rotator cuff partial tear in 4 cases (Fig. 2). 

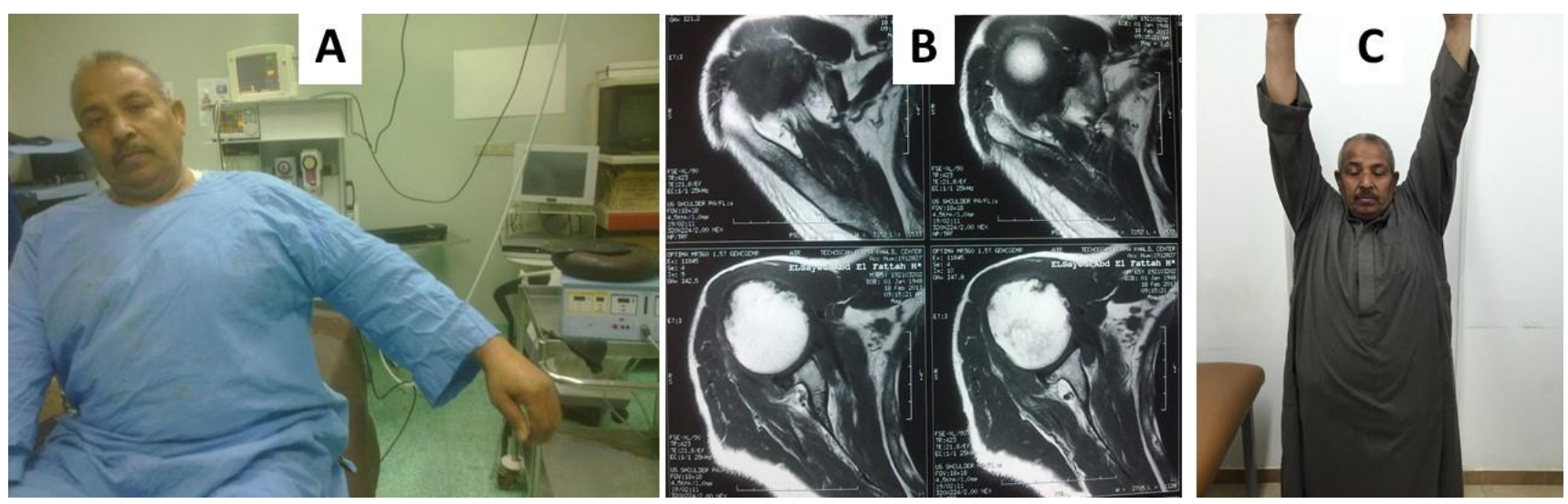

Figure 2) Case no.6: A) preoperative photo shows limitation of abduction range due to impingement, B) MRI preoperative, C) postoperative range of painless abduction 6 months postoperative.

\section{Complications:}

Early in the series, three patients complained of transient dysaesthesia in the distribution of the superficial branch of the radial nerve on the dorsum of the thumb. This probably resulted from inadequate padding of the traction device at the wrist. One patient experienced leaking from both the anterolateral and posterior portals but this ceased in one week with local wound care and antibiotic ointment. Another patient developed a local hematoma at the site of the anterior portal which resolved spontaneously. No ectopic bone formation has been seen in association with the bone fragments produced by mechanical burring. There has been no cases of deep infection. No compartment syndromes have developed, and distension has not involved the axillary area.

\section{DISCUSSION}

In 1985, Ellman [8] has devised the arthroscopic subacromial decompression (ASD) technique. His study performed a 1-3 year follow up on the pre and postoperative outcomes of 50 consecutive arthroscopic subacromial decompression (ASD) cases [9]. Eighty per cent of the cases had stage II impingement without rotator cuff tear and $20 \%$ had full-thickness rotator cuff tears.
Patients were evaluated according to the UCLA shoulder rating scale which assesses pain, function, range of motion, strength and patient satisfaction [17]. The majority of the cases $(88 \%)$ were rated satisfactory and the remainder (12\%) unsatisfactory. Arthroscopic subacromial decompression is now the gold standard as arthroscopy allows direct visualization inside the glenohumeral joint to detect other pathologies and the option to treat on the spot [14]. For ASD to be successful, the diagnosis has to be a primary mechanical (extrinsic) impingement process. Arthroscopic subacromial decompression is usually indicated for young and active patients with stage II impingement syndrome who are eager to resume their daily or sporting activities. Older patients may also undergo ASD if a series of conservative measures fail to address the structural impingement. Complications of ASD include acromial fractures or insufficient acromion or osteophyte removal, necessitating a revision procedure [18-21]. The operation can be carried out either in the lateral decubitus position or beach-chair position. The latter being favored by surgeons as this not only reduces the risk of neurological injury [22], but also enables easy manipulation of the 
humerus during surgery. In the procedure, three incisions or portals are created around the shoulder. The anterior portal is for saline inflow or outflow, posterior portal for camera viewing and lateral portal for instrumentation. Alternatively, two portals can also be created around the shoulder [23]. The anterior portal is used as an instrumentation portal and the posterior portal for the arthroscope [24].

The results of arthroscopic acromioplasty are usually good, with a satisfactory outcome in between $73 \%$ and $88 \%$ [8-14]. In this study, all patients had satisfactory results. According to UCLA score and 6 patients were excellent, eight patients had good results and two fair, but no poor results after one year postoperative. Pain relief was the most dramatic benefit but function also improved. The mean pain improved from 3 preoperative to 8.6 postoperative. Fourteen of the sixteen shoulders became completely pain free. Postoperative function averaged 8.9 on the UCLA scale (compared with 5.2 before operation). This implies the ability to perform activities of daily living (including driving, shopping and dressing), and to work above shoulder level with only, on occasion, slight restrictions.

Most studies of arthroscopic acromioplasty have concentrated on patients with stage II impingement. It seems probable that a longstanding tendinitis of this type can progress to fibrosis and thickening, which might explain the variable results in this group. An acromioplasty in such a patient is unlikely to be successful if the lesion is mainly in the tendon rather than the coraco- acromial arch [25-27]. Patients with long-standing pain suggestive of impingement, who do not respond to conservative treatment, are candidates for operation. With the possible exception of magnetic resonance imaging, the state of the rotator cuff and grading of the lesion is difficult determine by noninvasive methods [26-28].

\section{CONCLUSION}

In cases of primary impingement, calcific tendinitis, or partial thickness rotator cuff tears the arthroscopic acromioplasty and decompression, is the procedure of choice provided that no shoulder instability. The right indications and skilled hands, the results are better than the results of open acromioplasty, as the patients recover faster with less risk of deltoid muscle complications.

\section{REFERENCES}

1) Pujadas GM. Coracoacromial ligament syndrome. J Bone Joint Surg [Am] 1970; 52A: 1261.

2) Neer CS II. Anterior acromioplasty for the chronic impingement syndrome in the shoulder: a preliminary report. J Bone Joint Surg [Am] 1972; S4-A: 41-SO.

3) Neer CSII. Impingement lesions. Clin Orthop 1983; 173:70-7.

4) Hawkins RJ, Kennedy JC. Impingement syndrome in athletes. Am J Sports Med 1980; 8:151-8.

5) Post M, Collen J. Impingement syndrome: a review of late stage II and early stage III lesions. Orthop Trans 1985; 9:48.

6) Post M, Collen J. Impingement syndrome: a review of late stage II and early stage III lesions. Clin Orthop 1986; 207: 126-32.

7) Ragio CL, Warrea RF, Scuk:o T. Surgical treatment of impingement syndrome: 4 year follow-up. Orthop Trans 1985; 9:48-9.

8) Gahunia H K, Lemaire C, Cross A R, Babyn P, Kessler M J, Pritzker K P H. Osteoarthritis in Rhesus Macaques: Assessment of cartilage matrix quality by quantitative magnetic resonance imaging. In: Destruction in Arthritis and Osteoarthritis. Birkhauser Verlag, Basel 1993: 255-9.

9) Ellman H. Arthroscopic subacromial decompression: analysis of 1-3 year results. Arthroscopy 1987; 3:173-81.

10) Lehtinen J T, Markus J T, Maria A, David Z. William $\mathrm{P}$ and Jon $\mathrm{J} \quad \mathrm{P} \quad \mathrm{W}$. Practical assessment of rotator cuff muscle volumes 
using shoulder MRI; Acta Orthop Scand 2003; 74 (6): 722-729.

11) Ellman H. Arthroscopic treatment of impingement of the shoulder. In AAOS Instructional Course Lectures. 1989; 38:17785.

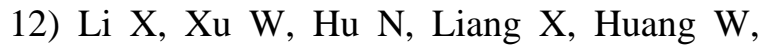
Jiang D, Chen H. Relationship between acromial morphological variation and subacromial impingement: A three-dimensional analysis. PLoS One. 2017 Apr 25; 12(4):e0176193.

13) Mackenzie TA, Herrington L, Horlsey I, Cools A. An evidence-based review of current perceptions with regard to the subacromial space in shoulder impingement syndromes: Is it important and what influences it? Clin Biomech. 2015; 30: 641648.

14) Balke M, Liem D, Greshake O, Hoeher J, Bouillon B, Banerjee M. Differences in acromial morphology of shoulders in patients with degenerative and traumatic supraspinatus tendon tears. Knee Surg Sports Traumatol Arthrosc. 2016; 24: 2200-2205.

15) Beard, DJ, Rees, JL, Cook, JA..., and on behalf of the CSAW study group. Arthroscopic subacromial decompression for subacromial shoulder pain (CSAW): a multicentre, pragmatic, parallel group, placebo-controlled, three-group, randomised surgical trial. (Published online Nov 16 Lancet. 2017; http://dx.doi.org/10.1016/S01406736(17)32457-1

16) Kawaguchi S1, Fukuta $S$, Tsutsui $T$, Matsuura T, Suzue N, Hamada D. Arthroscopic excision of unstable os acromiale associated with impingement syndrome: a case report. J Med Invest. 2016; 63(1-2):131-4.

17) Alison R, Thor A. B, Mathias B D, Julie S J, and David H C. Specific or general exercise strategy for subacromial impingement syndrome-does it matter? A systematic literature review and meta-analysis, BMC Musculoskelet Disord. 2017; 18: 158.

18) Amstutz HC, Sew Hoy AL, Clarke IC. UCLA anatomic total shoulder arthroplasty. Clin Orthop. 1981; 155:7-20.
19) Bigliani L U, Levine W N. Subacromial impingement syndrome. J Bone Joint Surg Am 1997; 79(12): 1854-68.

20) Bjornsson H, Norlin R, Knutsson A, Adolfsson L. Fewer rotator cuff tears fifteen years after arthroscopic subacromial decompression. J Shoulder Elbow Surg 2010; 19 (1): 111-5.

21) Saupe N, Pfirrmann CW, Schmid MR, Jost B, Werner CM, Zanetti M. Association between rotator cuff abnormalities and reduced acromiohumeral distance. AJR Am J Roentgenol 2006; 187(2): 376-382.

22) Shah N N, Bayliss N C, Malcolm A. Shape of the acromion: congenital or acquired-a macroscopic, radiographic, and microscopic study of acromion. J Shoulder Elbow Surg 2001; 10(4): 309-316.

23) Hearnden A, Tennent D. The cost of shoulder arthroscopy: a comparison with national tariff. Ann R Coll Surg Engl 2008; 90: 587-591.

24) Dattani R, Ramasamy V, Parker R, Patel VR. Improvement in quality of life after arthroscopic capsular release for contracture of the shoulder. Bone Joint J 2013; 95: 942946.

25) Jenkins PJ, Clement ND, Hamilton DF et al. Predicting the cost-effectiveness of total hip and knee replacement. Bone Joint J 2013; 95: 115-121.

26) Vitale MA, Arons RR, Hurwitz S. The rising incidence of acromioplasty. J Bone Joint Surg Am 2010; 92:1842-50.

27) Koester MC, George MS, Kuhn JE. Shoulder impingement syndrome. Am J Med 2005; 118:452-5.

28) Yu E, Cil A, Harmsen WS. Arthroscopy and the dramatic increase in frequency of anterior acromioplasty from 1980 to 2005: an epidemiologic study. Arthroscopy 2010; 26(9 Suppl):S142-S14. 